\title{
Chronic low Back Pain of Facet (Zygapophysial) Joint Origin: Is There A Difference Based on Involvement of Single or Multiple SPinal Regions?
}

\author{
Laxmaiah Manchikanti, MD, Joshua A. Hirsch, MD, and Vidyasagar Pampati, MSc
}

Facet (zygapophysial) joint pain can be diagnosed by anesthetization of the medial branch divisions of the dorsal rami. In accordance with the criteria established by the International Association for the Study of Pain, lumbar facet (zygapophysial) joints have been implicated as the source of chronic pain in $15 \%$ to $45 \%$ of the patients with chronic low back pain. The reasons for the wide variations have not been systematically evaluated. This study was designed to determine the prevalence of facet (zygapophysial) joint pain in patients suffering with only low back pain and compare this prevalence to the prevalence in patients with painful involvement of multiple regions of the spine.

A total of 300 patients in an interventional pain management setting, presenting and un-

Chronic pain is a common, persistent problem with relatively high incidence and low recovery rates (1). Among chronic pain problems, pain emanating from various structures of the spine constitutes the majority, despite the efforts expended in gathering information, research, prevention, treatment, and rehabilitation (2). Traditional beliefs indicate most episodes of low back will be shortlived, with $80 \%$ to $90 \%$ of attacks resolving in about six weeks, irrespective of the administration or type of treatment, with only $5 \%$ to $10 \%$ of patients develop persistent back pain $(3,4)$. In contrast, modern evidence indicates a prevalence of persistent low back pain from $32 \%$ to $79 \%$ at three months, and $35 \%$ to $75 \%$ at 12 months (5-14). Further, it has been shown that involvement of multiple regions, in addition to the lower back, in

From Pain Management Center of Paducah, Paducah, KY, and Harvard School of Medicine and Massachusettts General Hospital, Boston, MA. Address Correspondence: Laxmaiah Manchikanti, MD 2831 Lone Oak Road, Paducah, KY-42003.

E-mail:drm@apex.net

Funding: Nothing of value received from a commercial entity related to this research. dergoing diagnostic interventional procedures consecutively, either with involvement of a single region (low back only) or multiple spinal regions (low back pain and neck pain or thoracic pain) were evaluated. There were 150 patients in each group.

All patients were treated with diagnostic medial branch blocks with $1 \%$ lidocaine to test the presence of facet joint pain. Lidocaine-positive patients underwent a subsequent confirmatory block with $0.25 \%$ bupivacaine. Medial branches were blocked at two levels to block a single joint.

Prevalence of lumbar facet joint pain in patients with low back only was $21 \%$, compared to $41 \%$ of the patients with low back pain with involvement of other regions of the spine with controlled comparative local anesthetic blocks. A false-positive rate of $17 \%$ in patients with low back pain only and $21 \%$ in patients with involvement of multiple regions of the spine was demonstrated with single blocks.

This study demonstrated a lower incidence of facet joint pain in patients with spinal pain of a single region in the low back compared to the patients with multiple region involvement of the spine ( $21 \%$ vs $41 \%$ ), in an interventional pain management setting. These results may not be extrapolated to the general population or chronic low back pain population at large.

Keywords: Interventional pain management, facet joints, zygapophysial joints, medial branch blocks, controlled comparative local anesthetic blocks, false-positive rate, lidocaine, bupivacaine chronic pain patients is a common phenomenon $(15,16)$. Yeung et al $(15)$ in a cross-sectional study of 217 male workers from Hong Kong with varied levels of manual lifting experience showed that approximately $85 \%$ of lower back symptoms were associated with disorders in other body regions. Musculoskeletal symptoms for multiple body parts (two or more) were more prevalent (64\% of all workers) than those for single body regions (19\%). Manchikanti and Pampati (16) in evaluation of 372 patients in an interventional pain management setting showed that $79 \%$ had low back pain, and $56 \%$ of the patients had involvement of 2 regions.

Kuslich et al (17) identified facet joints, ligaments, fascia, muscles, intervertebral discs and nerve root dura as tissues capable of transmitting pain in the low back. Bogduk (18) resolved the issue of the existence of facet (zygapophysial) joint pain, which has been a topic of controversy in modern medicine. In fact, Bogduk (19) postulated that for any structure to be deemed a cause of back pain, it should have a nerve supply, be capable of causing pain similar to that seen clinically (ideally in normal volunteers), be suscep- tible to disease or injuries that are known to be painful, and have been shown to be a source of pain in patients using diagnostic techniques of known reliability and validity. Bogduk (18) also postulated that diagnostic blockade of a structure with a nerve supply with the ability to generate pain can be performed to test the hypothesis that the target structure is a source of the patient's pain.

In accordance with postulates of Bogduk $(18,19)$, the lumbar facet joints are innervated (20-22), they produce pain in normal volunteers (23-28), and relief of pain has been demonstrated by using diagnostic techniques of known reliability and validity (18, 29-40).

Blocks of the facet or zygapophysial joint can be performed in order to test the hypothesis that the target joint is the source of the patient's pain (18, 41). Facet joints can be anesthetized either with intraarticular injections of local anesthetic or by anesthetizing the medial branches of the dorsal rami that innervate the target joint. If pain is not relieved, the joint cannot be considered the source of pain, whereupon a new hypothesis about the source of pain is required 
(18). The source may be either in another joint or some other structure. If pain is relieved, the joint may be considered prima fasciae to be the source of pain, but steps need to be taken to ensure that the observed response is not false-positive (18). True-positive responses are secured by performing controlled blocks, either in the form of placebo injections of normal saline or comparative local anesthetic blocks, in which the same joint is anesthetized on two separate occasions but using local anesthetics with different durations of action. Comparative local anesthetic blocks are readily implemented if medial branch blocks are used to anesthetize zygapophysial joints. They may not be implementable for intraarticular blocks, for it is not known whether placement of local anesthetic in a relatively avascular environment, such as a joint space, affects its expected duration of action. Further, an injected capsule may leak into the adjacent neural foramen and result in blockade of the dorsal root ganglion and segmental nerves.

The rationale for using facet joint blocks for diagnosis is based upon the fact that lumbar facet joints have been shown to be capable of being a source of low back pain and referred pain in the lower limb in normal volunteers (23-28). Consequently, facet joints are possible sources of pain in patients presenting with low back pain and referred pain. There are no historical or clinical features that are either indicative or diagnostic of facet joint pain. Bogduk and Lord (41) described that because zygapophysial joint pain is neither an articular disorder nor a neurological disorder, not only should neurologic signs be absent, but they should also not be expected. In addition, facet joint pain does not meet the criteria of other joint pain, as joint pain is typically diagnosed on the grounds of swelling, tenderness, and restricted motion. In the context of zygapophysial joint pain, these signs are not available except for restricted motion. Thus, there is no reliable clinical means of implicating zygapophysial or facet joints as the source of low back pain in a given patient. Referral patterns described for lumbar facet joints are not only variable but also restricted (2328). Other structures in the same segment, such as the disc, may produce the same pattern of pain. Most maneuvers used in physical examinations are likely to stress several structures simultaneous- ly, especially the discs, muscles, and facet joints, thus failing to provide any reasonable diagnostic criteria. Multiple investigators have attempted unsuccessfully to correlate demographic features, pain characteristics, physical findings, and other signs and symptoms with diagnosis of facet joint pain; these were all proven unreliable $(18,19,42-46)$. Further, there are no valid and reliable means of identifying symptomatic lesions of the facet joint using currently available imaging technologies $(18,19,47-54)$. Thus, controlled diagnostic blocks with two separate local anesthetics (or placebo-controlled) are the only means of confirming diagnosis of facet joint pain.

The specificity of lumbar medial branch and L5 dorsal ramus blocks, as well as the ability of lumbar medial branch blocks to anesthetize zygapophysial joints was demonstrated by Dreyfuss et al (29) and Kaplan et al (30). Schwarzer et al (31-34) showed a prevalence of lumbar facet joint pain in chronic low back pain following injury in the United States of $15 \%$, with a false-positive rate of $32 \%$ with a single block and also demonstrated the inability to diagnose zygapophysial joint pain based on provocation response of joint injections. All these patients were young and were involved in either a work-related injury or motor vehicle injury. Most likely they had only lumbar region involvement without concurrent involvement of cervical or thoracic regions. Schwarzer et al (35) also showed the prevalence of zygapophysial joint pain in chronic low back pain in an Australian population in a rheumatology clinic as $40 \%$. In this study, patients were of an older age group with gradual onset rather than traumatic onset, likely involving more than one region of the spine in the same patient. Manchikanti et al (36-38) in the United States showed a prevalence of facet joint pain in chronic low back pain of $36 \%$ to $45 \%$ in a heterogeneous population in an interventional pain management setting. In a subgroup analysis, Manchikanti et al (39) showed the prevalence of facet joint pain as $28 \%$ in the occupational injury group compared to $44 \%$ in the gradual-onset group with significant differences. Manchikanti et al (40) also evaluated the prevalence of lumbar facet joint pain in patients with combined chronic low back and neck pain. They showed that the prevalence of lumbar facet joint pain was $40 \%$, with $94 \%$ of the patients with lumbar facet joint pain also exhibiting evidence of cervical facet joint pain.

Pathophysiology and etiology of facet joint pain is not clearly known at the present time. It has been assumed that the degeneration of the disc and facet joints would lead to spinal pain. However, these assumptions were based on the pathogenesis of the degenerative cascade in the context of a three-joint complex involving the articulation between two vertebrae consisting of the intervertebral disc and facet joints, because changes within each member of this joint complex will result in changes in the others (5557). Further, the potential for correlation of pain generators in the lumbar and cervical spine is exemplified by the demonstration of similar degeneration of discs in the cervical and lumbar spine in twins (58). Thus, it is conceivable that the prevalence of lumbar facet joint pain in chronic low back pain may be different based on the number of regions involved. Thus far in the literature, no investigator has evaluated the proportion of patients with involvement of a single region compared to patients with involvement of multiple regions of the spine. It seems that facet joint pain in chronic low back pain is variable between $15 \%$ and $45 \%$ in a heterogeneous population.

Based on the available evidence of facet joint involvement in chronic low back pain, we postulated the following:

i. Lower prevalence of lumbar facet joint pain in patients with involvement of one region (low back only) compared to multiple regions (lumbar and thoracic or cervical spine),

ii. Patients with involvement of a single region to be younger and with mode of onset following an incident,

iii. Lower prevalence of lumbar facet joint pain in patients with mode of onset following an incident compared to gradual onset, and

iv. Patients with involvement of multiple regions may have greater bilateral involvement.

This evaluation was undertaken to examine these postulates and also study the prevalence of facet (zygapophysial) joint pain in patients suffering with only low back pain, compared to patients with involvement of multiple regions (lumbar and thoracic or cervical spine). 


\section{Methods}

We evaluated 300 patients presenting and undergoing diagnostic interventional procedures consecutively, either with involvement of pain in a single region (low back only), Group I, or multiple spinal regions (low back and neck or thoracic), Group II, with 150 patients in each group. Patient allocation continued until there were 150 patients in each group. They were derived from a total of $378 \mathrm{pa}-$ tients with low back pain with or without involvement of other spinal regions, and from 625 total patients presenting for interventional pain management over a period of 19 months, evaluated, and treated by a single physician. Inclusion criteria included all the patients consenting to undergo diagnostic blocks with complaints of low back pain, patients 18 years to 90 years, patients without neurological deficits, patients who had pain for at least six months, patients without definite evidence of radiculopathy based on radiological or neurophysiologic testing, and patients who had failed conservative management. (Conservative management consisted of physical therapy, chiropractic management, exercises, drug therapy, bedrest, etc.) Furthermore, patients could not have received any type of injection therapy in the past two years.

Evaluation of the patients included history, physical examination, and evaluation of the results of all procedures and investigations. All patients consented and participated in the study after the nature of the study and the potential hazards of the procedures were explained to them.

All patients underwent diagnostic medial branch blocks with $1 \%$ lidocaine to test the presence of facet joint pain. Lidocaine-positive patients underwent a confirmatory block with bupivacaine. One percent lidocaine and $0.25 \%$ bupivacaine were utilized on separate occasions, usually three to four weeks apart. The injectate was prepared by a mixture of $2 \%$ lidocaine or $0.5 \%$ bupivacaine with equal volumes of Sarapin, with or without $2 \mathrm{mg}$ of methylprednisolone per $\mathrm{mL}$. The blocks were performed on the ipsilateral side in patients with unilateral pain or bilaterally in patients with bilateral or axial back pain. Medial branches were blocked at two levels to block a single joint. A 22gauge, 3.5-inch spinal needle was used to block the medial branches under intermittent fluoroscopy in the operating room, which involved medial branches at L1 through L4 and L5 dorsal ramus. Each nerve was infiltrated with $0.5 \mathrm{~mL}$ of either $1 \%$ lidocaine or $0.25 \%$ bupivacaine.

A definite response was defined as relief of at least $80 \%$ in the symptomatic area. Following each block, the patient was examined and previously painful movements were performed. In order to be considered positive, the response to a block had to last longer than two hours when lidocaine was used; and at least three hours or longer than the duration of effect from lidocaine when bupivacaine was used. Pain response was evaluated by numerical pain scale of 0-10. Intravenous access and mild sedation with midazolam were provided to all the patients.

Data were recorded in a database using Microsoft ${ }^{\circledR}$ Access $^{\circledR}$. The SPSS version 9.0 statistical package was used to generate frequency tables. Differences in proportions were tested using the Chi-square test. Fischer's exact test was used wherever the expected value was less than five. Results were considered statistically significant if the $P$ value was less than 0.05 .

\section{RESULTS}

Demogrpahic characteristics of the 300 patients included in the study are illustrated in Table 1. Mean age was higher in Group I compared to Group II. Gender distribution showed a greater number

Table 1. Demographic characteristics

\begin{tabular}{|c|c|c|c|}
\hline & & Group I & Group II \\
\hline Age (years) & Mean \pm SEM & $52^{\star} \pm 1.3$ & $44 \pm 1.1$ \\
\hline \multirow{2}{*}{ Gender } & Male & $45 \%(67)$ & $31 \%(46)$ \\
\hline & Female & $55 \%(83)$ & $69 \% *(104)$ \\
\hline Weight (lbs) & Mean + SEM & $185^{\star} \pm 3.8$ & $174 \pm 3 \cdot 7$ \\
\hline Height (inches) & Mean \pm SEM & $67 \pm 0.3$ & $66 \pm 0.3$ \\
\hline BMI & Mean \pm SEM & $29 \pm 0.6$ & $28 \pm 0.6$ \\
\hline $\begin{array}{l}\text { Duration of pain } \\
\text { (years) }\end{array}$ & Mean \pm SEM & $7 \pm 0.8$ & $9.6^{\star} \pm 0.8$ \\
\hline \multirow{4}{*}{ Mode of onset of pain } & Gradual & $49 \%(73)$ & $51 \%(76)$ \\
\hline & Work Comp Injury & $24 \%(36)$ & $7 \%(11)$ \\
\hline & $\begin{array}{l}\text { Motor Vehicle } \\
\text { Accident }\end{array}$ & $10 \%(16)$ & $19 \%(29)$ \\
\hline & Following an incident & $17 \%(25)$ & $23 \%(34)$ \\
\hline \multicolumn{2}{|c|}{ History of lumbar surgery } & $38 \% *(57)$ & $17 \%(25)$ \\
\hline \multirow{3}{*}{ Distribution of pain } & Right & $17 \%(25)$ & $14 \%(21)$ \\
\hline & Left & $20 \%(30)$ & $9 \%(13)$ \\
\hline & Bilateral & $63 \%(95)$ & $77 \%$ * (116) \\
\hline
\end{tabular}

* Indicates significant difference of female patients in Group II compared to Group I. Analysis of weight showed patients with higher weight in Group I compared to Group II. However, there was no difference in height or body mass index. Duration of pain was longer in Group II compared to Group I. There were no differences noted in mode of onset of pain. A greater proportion of patients underwent surgery in Group I. Bilateral distribution of pain was present in a greater number of patients in Group II.

Table 2 illustrates the results of evaluation of facet joint pain in the lumbar region for both groups. In Group I, 34\% of patients, or 51 , reported a definite response to lidocaine blocks. Confirmatory blocks with bupivacaine were performed in each of these patients. Of this group, 31 patients, or $21 \%$ of the total sample or $61 \%$ of lidocaine positive group, reported definite response with improvement in their pain. This provided a prevalence rate of facet joint pain for patients with chronic low back pain in single region of $21 \%$ (95\% CI, 14\%, 27\%).

In Group II, $57 \%$ of patients, or 85 , reported a definite response to lidocaine blocks. Confirmatory blocks with bupivacaine were performed in each of these 85 patients. Of this, 61 patients, or $41 \%$ of total sample or $72 \%$ of lidocaine positive group, reported definite response with improvement in their pain. This provided a prevalence rate of facet joint pain for pa- 
Table 2. Results of lumbar facet joint nerve blocks (single blocks with lidocaine and double blocks with lidocaine and bupivacaine)

\begin{tabular}{|c|c|c|c|c|}
\hline \multirow[b]{3}{*}{ Single Block } & \multicolumn{4}{|c|}{ Double Blocks (Lidocaine and Bupivacaine) } \\
\hline & \multicolumn{2}{|c|}{ Group I } & \multicolumn{2}{|c|}{ Group II } \\
\hline & Positive & Negative & Positive & Negative \\
\hline Positive & 31 & 20 & 61 & 24 \\
\hline Negative & & 99 & & 65 \\
\hline Prevalence & \multicolumn{2}{|c|}{$\begin{array}{c}\mathbf{2 1} \% \\
(95 \% \mathrm{Cl}, 14 \%, 27 \%)\end{array}$} & \multicolumn{2}{|c|}{$\begin{array}{c}\mathbf{4 1}^{* *} \\
\text { (95\% Cl, 33\%, 49\%) }\end{array}$} \\
\hline False-positive rate & \multicolumn{2}{|c|}{$\begin{array}{c}17 \% \\
\text { (95\% Cl, 10\%, 24\%) }\end{array}$} & \multicolumn{2}{|c|}{$\begin{array}{c}\mathbf{2 7} \% \\
\text { (95\% Cl, 18\%, 36\%) }\end{array}$} \\
\hline
\end{tabular}

* Indicates significant difference

Table 3. Subgroup analysis of prevalence of lumbar facet joint pain
\begin{tabular}{|l|l|c|c|c|}
\hline & & Group I & Group II & P value \\
\hline \multirow{2}{*}{ Gender } & Male & $22 \%$ & $35 \%$ & 0.198 \\
\cline { 2 - 5 } & Female & $19 \%$ & $43 \% *$ & 0.001 \\
\hline \multirow{2}{*}{ Age } & $<65$ yrs & $18 \%$ & $44 \% * \#$ & 0.000 \\
\cline { 2 - 5 } & $\geq 65$ yrs & $28 \%$ & $14 \%$ & 0.478 \\
\hline \multirow{2}{*}{ Distribution of pain } & Unilateral & $14 \%$ & $53 \% *$ & 0.000 \\
\cline { 2 - 5 } & Bilateral & $24 \%$ & $37 \%$ & 0.053 \\
\hline \multirow{2}{*}{ Mode of onset of the pain } & Gradual & $22 \%$ & $43 \% *$ & 0.006 \\
\cline { 2 - 5 } & Following an incident & $20 \%$ & $38 \% *$ & 0.0019 \\
\hline \multirow{2}{*}{ Duration of pain } & $<4$ years & $12 \%$ & $47 \% *$ & 0.000 \\
\cline { 2 - 5 } & $\geq 4$ years & $34 \% \# \#$ & $38 \%$ & 0.733 \\
\hline \multirow{2}{*}{ Previous surgery } & Yes & $12 \%$ & $40 \% *$ & 0.022 \\
\cline { 2 - 5 } & No & $26 \%$ & $41 \% *$ & 0.007 \\
\hline
\end{tabular}

* Indicates significant difference between groups

\# Indicates significant difference within the group $(p=0.045)$

$\#$ Indicates significant difference within the group $(p=0.000)$

tients with chronic low back pain in association with involvement of other regions of the spine of $41 \%$ ( $95 \%$ CI, 33\%, 49\%).

Prevalence of facet joint pain was significantly higher in Group II with $41 \%$ vs $21 \%$ in Group I ( $\mathrm{p}=0.000)$.

For the purposes of calculating the false-positive rate, all the patients who had no response to lidocaine were assumed to be true-negative, while all the patients who had a positive response to lidocaine and a negative response to bupivacaine were considered to be false-positive. The resultant false-positive rate was $17 \%$ for Group I ( $95 \%$ CI, 10\%, 24\%) and $27 \%$ for Group II (95\% CI, 18\%, 36\%). There was no significant difference in false-positive rates between Group I and Group II.

Table 3 illustrates subgroup analysis showing multiple differences. A greater proportion of female patients (43\%) in Group II presented with facet joint pain, compared to $19 \%$ in Group I. A greater proportion of patients in Group II with higher prevalence were below 65 years of age, with unilateral pain and duration of pain of less than 4 years.

\section{Discussion}

This controlled, prospective, prevalent study of lumbar facet joint pain in patients in an interventional pain management setting showed a prevalence of $21 \%$ (95\% CI, $14 \%, 27 \%)$ in patients with single region involvement, compared to $41 \%$ (95\% CI, 33\%, 49\%) in patients with involvement of multiple regions. The prevalence of a false-positive rate was established as $17 \%(95 \% \mathrm{CI}, 10 \%, 24 \%)$ in Group I and 27\% (95\% CI, 18\%, 36\%) in Group II with single-blocks. This is in accordance with our postulate that single region involvement will generate a significantly lower prevalence compared to multiple region involvement ( $21 \%$ vs. $41 \%)$. This is also similar to multiple previous reports (31-40). However, our postulate that patients with involvement of a single region are generally younger was not supported by the results of this study. In fact, patients were older in Group I compared to Group II. In addition, our postulate that the prevalence of lumbar facet joint pain would be lower based on the mode of onset of pain following an incident was also not supported by the results of this study. Finally, our postulate that most patients with multiple region involvement may have bilateral low back pain was confirmed by this evaluation, as $77 \%$ of the patients in Group II and 63\% of the patients in Group I presented with bilateral pain.

This study also showed a higher prevalence of lumbar facet joint pain in Group II, in a younger age group than elderly, $44 \%$ vs $15 \%$ ( $\mathrm{p}=0.045)$, in contrast to previous reports $(35,67)$. However, this was not the case in Group I. This may indicate the onset of facet joint pain at an earlier age with involvement of multiple regions in contrast to a single region. The shorter duration of pain in Group I was associated with a lower prevalence, $12 \%$ for those with pain of less than four years and $34 \%$ for those over with pain over four years $(p=0.000)$. There were no differences noted based on previous surgery or obesity. In Group II, younger patients ( $<65$ years vs $>65$ years of age) showed higher prevalence without any differences in Group I.

According to the postulates of Bogduk $(18,19)$ and the criteria established by the International Association for the Study of Pain (59), lumbar facet (zygapophysial) joints have been implicated as the source of chronic pain in $15 \%$ to $45 \%$ of the patients with chronic low back pain (31-40). Even then, it is often cited that a cause cannot be determined in $80 \%$ of patients with low back pain $(60,61)$ or, conversely, that a diagnosis is possible in only $10 \%$ to $15 \%$ of cases $(62,63)$. Though the source of this figure is difficult to track down (63), it seems to have been endorsed and enshrined by the report of the Quebec Task Force on low back pain in 1987 (64). When viewed in context, the figure is probably valid, but it reflects the opinions and practices in place in 1987 and before (63). However, since 1987, new diagnostic tests have been developed, evaluated, and implemented. If appropriate tests are used, a diagnosis of chronic low back pain can be made in at least $50 \%$ of cases, and perhaps in as many as $70 \%$ of cas- 
es (63). Bogduk and McGuirk (63) once again attested to the fact that there are no clinical features that distinguish lumbar zygapophysial joint pain from other causes of back pain. Further, they stated that it cannot be diagnosed by clinical examination or CT scanning, but it can only be diagnosed by controlled diagnostic blocks. Bogduk and McGuirk (65) described that medial branch blocks have been shown to have face validity. The studies of Dreyfuss et al (29) and Kaplan et al (30), showed that local anesthetic injected accurately onto the correct target points selectively infiltrates the target nerve, does not anesthetize any adjacent structures that might be an alternative source of pain to the zygapophysial joint, and medial branch blocks have been shown to protect normal volunteers from pain provoked experimentally from an anesthetized joint. Further, Bogduk and McGuirk (65) stated that in order to have construct validity, medial branch blocks must be controlled, as single diagnostic blocks carry a false-positive rate of $24 \%$ to $47 \%$. They also described the most convenient form of control in evaluation of spinal pain of facet joint origin is the use of comparative local anesthetic blocks. Furthermore, establishing a diagnosis of facet joint pain provides the patient with a valid diagnosis, dispels any concerns about the source of their pain, and precludes the need for any further investigations in the pursuit of a diagnosis (65). Subgroup analysis of the prevalence of facet joint pain showed a prevalence of $38 \%$ in men, compared to $43 \%$ in women; $43 \%$ in non-smokers, compared to $41 \%$ in heavy smokers; and $28 \%$ in occupational injury patients, compared to $40 \%$ with a history of gradual onset (39). The present study showed no significant difference in prevalence of lumbar facet joint pain within the groups based on mode of onset of pain (injury vs gradual onset). It was also shown that the prevalence of facet joint pain was lower in post-lumbar laminectomy patients or patients younger than 65 years of age, compared to nonsurgical patients or the elderly, respectively $(66,67)$. This study, in contrast to previous studies, showed no difference in prevalence based on previous surgery. In addition, the results also showed a higher prevalence in the younger age group in Group II. It was also shown that obesity played no role (68).

Criticism may be forwarded that we did not utilize placebo-controlled diagnostic blocks. Instead, we utilized controlled, comparative local anesthetic blocks of the medial branches, based in a private practice setting and validation of controlled comparative local anesthetic blocks. The controlled, comparative local anesthetic blocks utilized in this study have been shown to be reliable and reproducible against challenge with placebo $(69,70)$. Thus, the criticism of lack of placebo control is not valid. Based on the validation of comparative local anesthetic blocks, as well as logistical and/or ethical considerations prohibiting the use of placebo controls with normal saline in conventional practice in the United States, controlled comparative local anesthetic blocks is the best alternate to placebo control. Once again, this study validates the concept of comparative local anesthetics and the lack of reliability of results derived from single anesthetic block.

Criticism may also be advanced based on the fact that we performed medial branch blocks, rather than intraarticular injections. However, one of the reported drawbacks of local anesthetic control is that comparative local anesthetic blocks may not be implementable for intraarticular blocks because it is not known whether the placement of local anesthetic in a relatively avascular environment, such as a joint space, affects its expected duration of action. Thus, we employed medial branch blocks utilizing comparative local anesthetic agents in all cases. The significant false-positive rate of $17 \%(95 \% \mathrm{CI}, 10 \%, 24 \%)$ in Group I and $27 \%(95 \% \mathrm{CI}, 18 \%, 36 \%)$ in Group II with single-block, once again, validates the necessity of controlled, comparative local anesthetic blocks rather than a single block. The value of confirmatory blocks with a separate local anesthetic has been demonstrated for lumbar zygapophysial (facet) blocks repeatedly (31-40).

The theory that testing a patient first with lidocaine and subsequently with bupivacaine provided a means of identifying placebo response has been tested and proven (69-73). In fact, Barnsley et al (69) and Lord et al (70) included blinded comparison of test and reference.

This study may be criticized for using depomethylprednisolone and Sarapin along with the local anesthetic. However, the validity of lumbar medial branch blocks with adjuvant solutions was demonstrated in a previous study (36).
Finally, we may also be criticized for not utilizing other criteria to establish the diagnosis of facet joint pain. However, there are no clinical, physical, electrophysiologic, or radiologic criteria to diagnose or to rule out facet joint pain $(18,19,23$ $28,42-54)$. Our selection criteria excluded patients with disc herniation and radicular pain. Furthermore, we also have excluded patients with neurological deficits and abnormalities not only on radiological testing, but also neurophysiologic testing and also patients who have failed to respond to conservative management.

In summary, these results show a low prevalence of $21 \%$ of lumbar facet joint involvement in chronic low back pain with involvement of a single region and a higher prevalence of $41 \%$ in patients with concurrent involvement of other regions of the spine. These results are specifically limited to an interventional pain management setting, in patients who have failed conservative management, patients who have suffered pain for at least six months, for patients without disc herniation, and patients without neurophysiological abnormalities or radicular involvement. These results may not be extrapolated to the general population or even chronic pain population in other settings.

\section{CONCLUSION}

The study showed a prevalence of lumbar facet joint pain in patients presenting for interventional pain management of $21 \%$ for patients with chronic low back pain without concurrent involvement of other regions of the spine, and of $41 \%$ for patients with concurrent involvement of other regions of spine. This study also demonstrated unreliability of single blocks to diagnose facet joint pain with a false-positive rate of $17 \%$ and $27 \%$ consecutively in Group II and III. The results of this study emphasize the involvement of lumbar facet joints in chronic low back pain in a significant number of patients in an interventional pain management setting. The results also provide insight into facet joint involvement in chronic low back pain by demonstrating a higher prevalence in patients with chronic low back pain concurrent with involvement of other spinal regions. This study also provides basis to two of our postulates: lower prevalence in single region, and a greater proportion of patients with bilateral distribution of pain in patients with multiple regions. This study failed to provide 
basis for our other assumptions, including younger age group and mode of onset following an incident to be associated with a single region and lower prevalence of lumbar facet joint pain.

Author Affiliation:
Laxmaiah Manchikanti, MD
Medical Director
Pain Management Center of Paducah
2831 Lone Oak Road
Paducah, Kentucky 42003
E-mail: drm@apex.net
Joshua A. Hirsch, MD
Harvard School of Medicine
Department of Interventional
Radiology
Massachusetts General Hospital
55 Blossom St., Gray 289
Boston, Massachusetts 02114
E-mail: jahirsch@partners.org
Vidyasagar Pampati, MSc
Statistician
Pain Management Center of Paducah
2831 Lone Oak Road
Paducah, Kentucky 42003
E-mail: sagar@thepainmd.com

\section{RefERENCES}

1. Elliott AM, Smith BH, Hannaford PC et al. The course of chronic pain in the community: Results of a 4-year follow-up study. Pain 2002; 99:299-307.

2. Hellsing AL, Bryngelsson IL. Predictors of musculoskeletal pain in men: A twentyyear follow-up from examination at enlistment. Spine 2000; 25:3080-3086.

3. Anderson GBJ, Svensson HO. The intensity of work recovery in low back pain. Spine 1983; 8:880-887.

4. Svensson HO, Andersson GBJ, Johansson $\mathrm{S}$ et al. A retrospective study of low back pain in 38- to 64-year old women: Frequency and occurrence and impact on medical services. Spine 1988; 13:548552.

5. Waxman R, Tennant A, Helliwell P. A prospective follow up study of low back pain in the community. Spine 2000; 25:20852090.

6. van den Hoogen HJ, Koes BW, Deville W et al. The prognosis of low back pain in general practice. Spine 1997; 22:1515-1521.

7. Croft PR, Papageorgiou AC, Thomas E et al. Short-term physical risk factors for new episodes of low back pain. Prospective evidence from the South Manchester Back Pain Study. Spine 1999; 24:15561561.

8. Carey TS, Garrett JM, Jackman A et al. Re- currence and care seeking after acute back pain. Results of a long-term followup study. North Carolina Back Pain Project. Med Care 1999; 7:157-164.

9. Miedema HS, Chorus AMJ, Wevers CWJ et al. Chronicity of back problems during working life. Spine 1998; 23:2021-2029.

10. Thomas E, Silman AJ, Croft PR et al. Predicting who develops chronic low back pain in primary care. A prospective study. Brit Med J 1999; 318:1662-1667.

11. Wahlgren DR, Atkinson JH, Epping-Jordan JE et al. One-year follow up of first onset low back pain. Pain 1997; 73:213-221.

12. Schiottz-Christensen B, Nielsen GL, Hansen VK et al. Long-term prognosis of acute low back pain in patients seen in general practice: A 1-year prospective follow-up study. Fam Pract 1999; 16:223-232.

13. Ferguson SA, Marras WS, Gupta P. Longitudinal quantitative measures of the natural course of low back pain recovery. Spine 2000; 25:1950-1956.

14. Vingård E, Mortimer M, Wiktorin C et al. Seeking care for low back pain in the general population: A two-year follow-up study: Results from the MUSIC-Norrtalje Study. Spine 2002; 27:2159-2165.

15. Yeung SS, Genaidy A, Deddens J et al. Prevalence of musculoskeletal symptoms in single and multiple body regions and effects of perceived risk of injury among manual handling workers. Spine 2002; 27:2166-2172.

16. Manchikanti L, Pampati V. Research designs in interventional pain management: Is randomization superior, desirable or essential? Pain Physician 2002; 5:275-284.

17. Kuslich SD, Ulstrom CL, Michael CJ. The tissue origin of low back pain and sciatica: A report of pain response to tissue stimulation during operation on the lumbar spine using local anesthesia. Orthop Clin North Am 1991; 22:181-187.

18. Bogduk N. International Spinal Injection Society guidelines for the performance of spinal injection procedures. Part 1: Zygapophyseal joint blocks. Clin J Pain 1997; 13:285-302.

19. Bogduk N (ed). Low back pain. In: Clinical Anatomy of the Lumbar Spine and Sacrum, ed 3. Churchill Livingstone, New York, 1997:187-214.

20. Bogduk N, Wilson AS, Tynan W. The human lumbar dorsal rami. J Anat 1982; 134: 383-397.

21. Suseki K, Takahashi Y, Takahashi K et al. Innervation of the lumbar facet joints. Spine 1997; 22:477-485.

22. Bogduk N. The innervation of the lumbar spine. Spine 1983; 8:286-293.

23. Hirsch D, Inglemark B, Miller M. The anatomical basis for low back pain. Acta Orthop Scand 1963; 33:1.

24. Mooney V, Robertson J. The facet syndrome. Clin Orthop 1976;115:149-156.

25. McCall IW, Park WM, O’Brien JP. Induced pain referral from posterior elements in normal subjects. Spine 1979;4:441-446.

26. Marks R. Distribution of pain provoked from lumbar facet joints and related structures during diagnostic spinal infiltration. Pain 1989; 39:37-40.

27. Fukui $\mathrm{S}$, Ohseto K, Shiotani $M$ et al. Distribution of referral pain from the lumbar zygapophyseal joints and dorsal rami. Clin J Pain 1997; 13:303-307.

28. Windsor RE, King FJ, Roman SJ et al. Electrical Stimulation Induced Lumbar Medial Branch Referral Patterns. Pain Physician 2002; 5:347-354.

29. Dreyfuss P, Schwarzer AC, Lau P et al. Specificity of lumbar medial branch and $L_{5}$ dorsal ramus blocks: A computed tomography study. Spine 1997; 22:895-902.

30. Kaplan M, Dreyfuss P, Halbrook B et al. The ability of lumbar medial branch blocks to anesthetize zygapophysial joint. Spine 1998; 23:1847-1852.

31. Schwarzer AC, Aprill CN, Derby $R$ et al. Clinical features of patients with pain stemming from the lumbar zygapophysial joints. Is the lumbar facet syndrome a clinical entity? Spine 1994; 19:1132-1137.

32. Schwarzer AC, Aprill CN, Derby R et al. The relative contributions of the disc and zygapophyseal joint in chronic low back pain. Spine 1994; 19:801-806.

33. Schwarzer AC, Derby R, Aprill CN et al. The value of the provocation response in lumbar zygapophysial joint injections. Clin J Pain 1994; 10:309-313.

34. Schwarzer AC, Aprill CN, Derby R et al. The false-positive rate of uncontrolled diag nostic blocks of the lumbar zygapophysial joints. Pain 1994; 58:195-200.

35. Schwarzer AC, Wang S, Bogduk $\mathrm{N}$ et al. Prevalence and clinical features of lumbar zygapophysial joint pain: A study in an Australian population with chronic low back pain. Am Rheum Dis 1995; 54:100106.

36. Manchikanti L, Pampati V, Fellows B et al. The diagnostic validity and therapeutic value of lumbar facet joint nerve blocks with or without adjuvant agents. Cur Rev Pain 2000; 4:337-344.

37. Manchikanti L, Singh V, Pampati V et al. Evaluation of the relative contributions of various structures in chronic low back pain. Pain Physician 2001; 4:308-316.

38. Manchikanti L, Pampati V, Fellows B et al. Prevalence of lumbar facet joint pain in chronic low back pain. Pain Physician 1999; 2:59-64.

39. Manchikanti L, Singh V, Fellows B et al. Evaluation of influence of gender, occupational injury, and smoking on chronic low back pain of facet joint origin: A subgroup analysis. Pain Physician 2002; 5:30-35.

40. Manchikanti L, Singh V, Pampati V et al. Is there correlation of facet joint pain in lumbar and cervical spine? An evaluation of prevalence in combined chronic low back and neck pain. Pain Physician 2002; 5 : 365-371. 
41. Bogduk N, Lord S. Cervical zygapophysial joint pain. Neurosurgery 1998; 8:107-117.

42. Revel ME, Listrat VM, Chevalier XJ et al. Facet joint block for low back pain. Identifying predictors of a good response. Arch Phys Med Rehabil 1992; 73:824-828.

43. Revel M, Poiraudeau S, Auleley GR et al. Capacity of the clinical picture to characterize low back pain relieved by facet joint anesthesia. Proposed criteria to identify patients with painful facet joints. Spine 1998; 23:1972-197.

44. Manchikanti L, Pampati V, Fellows B et al. The inability of the clinical picture to characterize pain from facet joints. Pain Physician 2000; 3:158-166.

45. Schwarzer AC, Derby R, Aprill CN et al. Pain from the lumbar zygapophysial joints: A test of two models. J Spinal Disord 1994; 7:331-336.

46. Manchikanti L, Staats $P$, Singh $V$ et al. Evidence-based practice guidelines for interventional techniques in the management of chronic spinal pain. Pain Physician 2003; 6:3-80.

47. Schwarzer AC, Wang SC, O'Driscoll D et al. The ability of computed tomography to identify a painful zygapophysial joint in patients with chronic low back pain. Spine 1995; 20:907-912.

48. Schwarzer AC, Scott AM, Wang S et al. The role of bone scintigraphy in chronic low back pain: Comparison of SPECT and planar images and zygapophysial joint injection. Aust N Z J Med 1992; 22:185.

49. Magora A, Bigos SJ, Stolov WC et al. The significance of medical imaging findings in low back pain. Pain Clinic 1994; 7:85-166.

50. Selby DK, Paris SV. Anatomy of facet joints and its clinical correlation with low back pain. Contemporary Orth 1981; 3:10971103.

51. Fairbank JCT, Park WM, McCall IW et al. Apophyseal injection of local anesthetic as a diagnostic aid in primary low back pain syndromes. Spine 1981; 6:598-605.

52. Helbig T, Lee CK. The lumbar facet syndrome. Spine 1988; 13:61-64.

53. Dreyfuss PH, Dreyer SJ, Herring SA. Con- temporary concepts in spine care: Lumbar zygapophysial (facet) joint injections. Spine 1995; 20:2040-2047.

54. Dreyfuss PH, Dreyer SJ. Lumbar zygapophysial (facet) joint injections. Contemporary Concepts in Spine Care, North American Spine Society, LaGrange, IL, September 2001.

55. Kirkaldy-Willis WH, Wedge JH, Yong-Hing K et al. Pathology and pathogenesis of lumbar spondylosis and stenosis. Spine 1978; 3:319-327.

56. Fujiwara A, Tamai K, An HS. The relationship between disc degeneration, facet joint osteoarthritis, and stability of the degenerative lumbar spine. J Spinal Disord 2000; 13:444-450.

57. Thompson RE, Pearcy MJ, Downing KJW. Disc lesions and the mechanics of the intervertebral joint complex. Spine 2000; 25:3026-3035.

58. Sambrook PN, MacGregor AJ, Spector TD. Genetic influences on cervical and lumbar disc degeneration: A magnetic resonance imaging study in twins. Arthritis Rheum 1999; 42:366-372.

59. Merskey H, Bogduk N. Classification of chronic pain: Descriptions of chronic pain syndromes and definitions of pain terms. 2nd ed. IASP Press, Seattle, 1994.

6o. Kirwan EO. Back pain. In: Wall PD, Melzack R (eds). Text Book of Pain, 2nd ed. Churchill Livingstone, Edinburgh, 1989: 335-340.

61. White AA. The 1980 symposium and beyond. In Frymoyer JW, Gordon SL (eds). New Perspectives on Low Back Pain. American Academy of Orthopaedic Surgeons, Park Ridge, 1989:3-17.

62. Frymoyer W. Epidemiology. In Frymoyer JW, Gordon SL (eds). New Perspectives on Low Back Pain. American Academy of Orthopaedic Surgeons, Park Ridge, 1989:19-33.

63. Bogduk N, McGuirk B (eds). Causes and sources of chronic low back pain. In Medical Management of Acute and Chronic Low Back pain. An Evidence-Based Approach Pain Research and Clinical Management,
Vol. 13. Elsevier Science BV, Amsterdam, 2002:115-126.

64. Quebec Task Force on Spinal Disorders. Scientific approach to the assessment and management of activity-related spinal disorders: A monograph for clinicians. Spine 1987; 12:S1-59.

65. Bogduk N, McGuirk B (eds). Precision diagnosis. In Medical Management of Acute and Chronic Low Back pain. An Evidence-Based Approach Pain Research and Clinical Management, Vol. 13. Elsevier Science BV, Amsterdam, 2002:169-176.

66. Manchikanti L, Pampati V, Baha A et al. Contribution of facet joints to chronic low back pain in postlumbar laminectomy syndrome: A controlled comparative prevalence evaluation. Pain Physician 2001; 4: 175-180.

67. Manchikanti L, Pampati V, Rivera J et al. Role of facet joints in chronic low back pain in the elderly: A controlled comparative prevalence study. Pain Practice 2001; 1:332-337.

68. Manchikanti L, Pampati V, Singh V et al. Evaluation of the role of facet joints in persistent low back pain in obesity: A controlled, prospective, comparative evaluation. Pain Physician 2001; 4:266-272.

69. Barnsley L, Lord S, Bogduk N. Comparative local anesthetic blocks in the diagnosis of cervical zygapophysial joints pain. Pain 1993; 55: 99-106.

70. Lord SM, Barnsley L, Bogduk N. The utility of comparative local anesthetic blocks versus placebo-controlled blocks for the diagnosis of cervical zygapophysial joint pain. Clin J Pain 1995; 11:208-213.

71. Bonica JJ. Local anesthesia and regional blocks. In Wall PD, Melzack R (eds). Textbook of Pain, 2nd ed. Churchill Livingstone, Edinburg, 1989:724-743.

72. Bonica JJ, Buckley FP. Regional analgesia with local anesthetics. In Bonica JJ (ed). The Management of Pain. Lea \& Febiger, Philadelphia, 1990; 2:1883-1966.

73. Boas RA. Nerve blocks in the diagnosis of low back pain. Neurosurg Clin North Am 1991; 2:806-816. 
